\title{
Research on Teaching Reform Mode of "Signal and System" in the "Internet +" Context \\ Hao Sun
}

\author{
Address: Department of Electronic Science and Technology, Xi'an Fanyi University, Taiyi \\ Palace, Chang'an District, Xi'an, Shaanxi Province, China \\ Zip code: 710105 Tel: 17791282219 Email: 76802682@qq.com \\ Project of This Paper: Project of Educational Science Planning in Shaanxi Province in 2017 \\ Project No. : SGH17H475
}

Keywords: Internet +; Signal and system; Course teaching reform

\begin{abstract}
Signal and system" is an important technical basic course of electronic information specialty. In view of the present situation of the difficult course, combining the current situation of students and their practical teaching experience, we think that the lack of solid foundation of mathematics, lack of practical links and the challenges of Internet to the traditional classroom teaching are the main reasons for the difficulty of teaching.

With the emergence of the "Internet + " educational philosophy, the traditional "signal and system" curriculum teaching model also need to be reformed to meet the "application" talent training requirements. I think we can start from the "Internet + Resources", "Internet + Practice" these two directions, make full use of a large amount of teaching resources and convenient technical means from the Internet platform to strengthen the training of students' practice ability and encourage students to actively participate in various practice activities, and ultimately reach the goal that the students are cultivated to be "application" talents with a solid theoretical basis.
\end{abstract}

\section{Introduction}

"Signal and System" course is an important technical foundation course for electronic information professionals. The course is a highly theoretical course both from the teaching content to the teaching purpose. It not only has strong links with a lot of professional courses (such as communication principle, digital signal processing, automatic control, etc.) of electronic information specialty, but also the teaching content are related to higher mathematics, linear algebra and many other math courses content, which is compulsory course for the majority of electronic information undergraduates[1]; From the engineering practice point of view, the basic analytical methods and system principles of the course have been widely used in the fields of communication, automatic control, signal and information processing [2]. From the development point of view, the rapid arrival of "Internet + " has already produced far-reaching impact on the traditional teaching mode.

It can be seen how to effectively use the innovative teaching idea and the massive online educational resources in the background of "Internet + " to improve the teaching quality of the "signal and system" course, to improve the teaching effect, to cultivate and improve the students' independence analysis of the problems and the ability to solve the problem, so that students get a solid theoretical basis of the "application" talent, which is a very meaningful work. To this end, I started from the practical experience for many years to make a deep exploration of the teaching reform of the "signal and system" course.

\section{Analysis of Problems Encountered in the "Signal and System" Course}

Signal and system has always been a hard-to-learn course, I have engaged in this course teaching for nearly eight years, summed up that in the teaching process, the encountered main problems are showed as the following three aspects: 
Not Solid Enough Foundation of Mathematics. Xi'an Fanyi University I was engaged in belongs to the private application institutions, and thus the quality of students received generally are not high, especially the mathematical foundation is generally weak. The "signal and system" course requires a very solid mathematical foundation, especially the linear differential equation solution of higher mathematics, calculus transformation and other knowledge are widely exist in the curriculum of the knowledge system, which set up a very difficult "mountains "for students to go beyond. This point can be demonstrated particularly evident in the teaching of the two core systems of knowledge, such as "Fourier transform" and "Laplace transformation", which are often showed in the teacher's formula in the classroom, even though the nature of the story is in full swing, but students expression is at a loss, and even begin to play their mobile phone. The root of this phenomenon is that the student's mathematical foundation is not solid enough, leading to disjoint of "teaching" and "learning" seriously.

Inadequate Practice. "Signal and system" course is generally in the second semester of the undergraduate semester, because in this semester higher mathematics courses basically finished, follow-up courses have not yet begun, so suitable for the opening of "signal and system". However, this has brought a new problem: sophomore students are not in-depth contact with the community, and thus they don't have deep recognition on the wide application of actual production and life. The traditional signal and system course teaching focuses on the study of theoretical knowledge, in the practice, the verification experiments will be in the main position. This kind of teaching methods paying attention to the theory while light practice have become increasingly unsuited to the college education reform model and personnel training mode of the current "applied undergraduate" [3].

Challenges from Internet to Traditional Classroom Teaching. Smart phones (hereinafter referred to as mobile phones) has become indispensable thing for all adults today, but I love it while hate it, too. Because it has become the biggest challenger for the traditional classroom and teachers. Through the mobile surfing and real-time interactive "bow family" become "landscape" in the traditional classroom that can not be more ignored [4]. Students can use the mobile phone to find information, see micro-class video, see the teaching teacher's audio and video, live classroom teaching ... And even can do the teaching and learning, to correct the teacher lectures when there are some mistakes, which is unthinkable in the traditional classroom. To some extent, the challenge of mobile phones to teachers and traditional classrooms is essentially the challenge of mobile Internet to traditional classroom teaching mode.

\section{Discussion on Teaching Reform of the "Signal and System" in "Internet +" Background}

After Prime Minister Li Keqiang put forward the concept of "Internet +", its connotation and extension in different areas have different interpretations [6]. If this concept is applied to the teaching reform of the "signal and system" course, I think that the teaching reform can be carried out from the following three aspects:

"Internet + Resources". Effectively using the Internet can provide a large amount of teaching resources for us, which can greatly improve the breadth and depth of classroom teaching. This is reflected in the following aspects:

(1) the excellent teacher was invited to the classroom

With the help of the Internet, we can download the resource that teachers share courseware, micro classes, video, experience and other resources on the Internet to study at anytime and anywhere, that is to say, which is equivalent to we have become a teacher "anonymous" student, are of importance to improve students' level of knowledge and ability.

(2) Introduce new results into the classroom

We can use the Internet to collect unique insights of the latest research results on the "signal and system" of the subject the first time, but also make a variety of new teaching methods, teaching methods and teaching strategies be applied to classroom teaching, which can greatly improve the freshness and a high degree of attention for the students in the teaching process.

(3) Apply new technology to teaching

At present, more and more schools and teachers have encouraged students to use their mobile 
phones in the classroom to inquire relevant information on a specific problem; use WeChat or QQ to ask questions, Q \& A, assignments, etc.; encourage students to use the network to share classroom notes. So that both no matter in the classroom or out of the classroom, we can use the Internet for teaching and communication, so that the classroom teaching also penetrate into the student's fragmented learning, and then students continue to learn the knowledge missed in the class and make more progress.

"Internet + Practice". In view of the weak links in the practice of traditional classroom teaching, we can use the Internet to strengthen the cultivation of students' practical ability, which can be reflected in the following aspects:

(1)Teaching content is no longer rigidly adhere to the teaching materials and syllabus, can extract typical materials and typical cases from the network and life practice for teaching.

When studying the content of "Signal and System" learning system analysis and system design, we can first select and broadcast a video on the industrial production, and then from the perspective of systematic analysis to teach them how to understand this production process, and finally inspire students how to improve and design a new production process to increase production or efficiency, so that students throughout the learning process to comprehend the similarities and differences of book theory and actual production.

(2)Actively create better internships and practice conditions for students, and encourage students to participate in various forms of practical activities.

We should make full use of the Internet, to find and select the appropriate student internship units for students, construct practice training base, so that students can get deepening understanding of theoretical courses in the practice of training, and exercise their own ability, and can not just be satisfied with how many experiments the lab can do. At the same time, we should actively create conditions to encourage and guide students to participate in various competitions (especially electronic design competition), to declare all kinds of college students innovative business projects, so that students get continuous improvement for their own innovation ability and business level in the practice, and ultimately the students will be developed to be a "application" talent with solid theoretical basis.

\section{Conclusion}

The opening of "Internet + " education era brings challenges for the classroom teaching of "signal and the system" subject, but also produces the opportunity. I hope that I could do my effort in the reform of subverting the traditional teaching mode for the cultivation of the school's "application" talent.

\section{Acknowledgements}

Thesis project: Project of Educational Science Planning in Shaanxi Province in 2017

Project number: SGH17H475

\section{References}

[1] Zhang Min. Signal and system course teaching reform and research [J]. Journal of Beijing City University, 2008, (3): 36-39.

[2] Li Xianglin. "Signal and system" teaching reform [J]. Higher Education Forum, 2005,12 (6): 159-162.

[3] Zhang Dali, Liao Xiaowei. Based on the application of personnel training "signal and system" teaching reform-take Huainan Teachers College as an example [J], Huainan Teachers College, 2013, (4).

[4] In classroom to play mobile phone become an "international problem", the teacher said, the 
phone becomes a "non-refundable third party", Xinhua, 2014.6.2

[5] Wang Zhuli, Li Xiaoyu, Lin Jin. Smart phone and "Internet +" classroom - new thinking, new path of information technology and curriculum integration [J], Distance Education, 2015, (4) 14-21.

[6] Tan Linglong, Chen Yehui, Wang Qing, Sun Yannan. Teaching reform of signal processing course based on the "Internet + education" [J], Shaoguan University, 2017, 38 (5).

[7] Zhao Xin, Tai Junjun. "Signal and System" teaching model reform and practice research [A], Proceedings of 2011 National Teaching Seminar on Cryptography and Information Security (NTS-CIS 2011) Vol.1 [C], 2011. 